\title{
Towards positive institutions: Positive practices and employees' experiences in higher education institutions
}

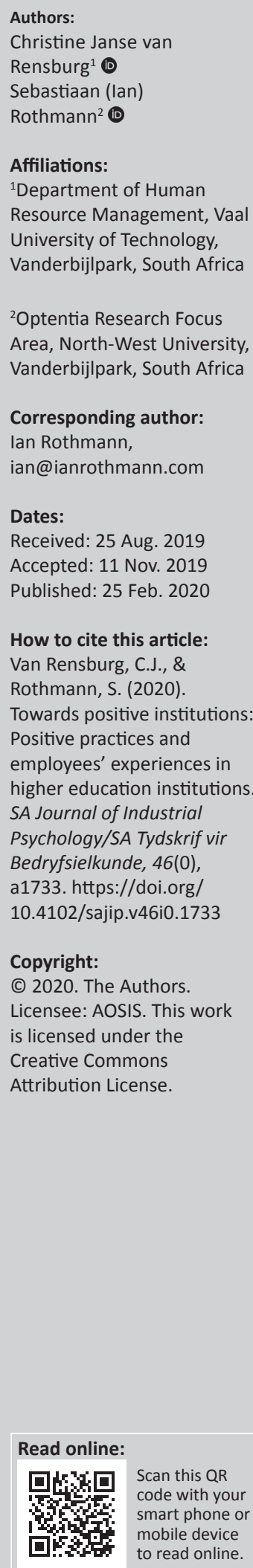

Orientation: Positive organisational functioning is a paradox. Both positive and negative tendencies could enable positive functioning. While an overemphasis on either the positive or the negative aspect is dysfunctional, positive factors must be given extra emphasis for positivity to occur because negativity usually dominates.

Research purpose: This study aimed to investigate how positive organisational practices relate to job demands and resources, person-environment fit and well-being.

Motivation for the study: Work in organisations and experiences thereof are not always positive. However, focussing on positive practices even when the context and experiences thereof are negative might facilitate positive functioning of individuals and their institutions.

Research approach/design and method: A cross-sectional survey design was used with a convenience sample of 339 academic employees from three higher education institutions in South Africa. The Positive Practices Questionnaire, the Job Demands-Resources Scale, two perceived person-environment fit scales and the Flourishing-at-Work Scale - Short Form were administered.

Main findings: Results from latent profile analyses provided evidence of four latent profiles. Analysis showed that a perceived lack of positive practices in institutions was associated with perceptions of overload, lack of role clarity, poor supervisor and co-worker relationships, lack of person-environment fit, and reduced emotional, psychological and social well-being.

Practical/managerial implications: Interventions should be employed by leaders to address positive practices in higher education institutions.

Contribution/value-add: This study contributes to scientific knowledge regarding the relations between positive organisational practices and experiences of job demands and resources, person-environment fit and well-being of academics.

Keywords: positive organisational practices; job demands and resources; person-environment fit; well-being; organisational behaviour.

\section{Introduction}

Positive organisational functioning is a paradox (Cameron, 2008). On the one hand, natural human inclinations towards the positive and heliotropic tendencies foster a focus on positive practices. On the other hand, human beings react more strongly to negative than to positive stimuli; therefore, the presence of negative events overshadows positive events. Both positive and negative tendencies could enable positive functioning. A positive environment provides positive energy, which is heliotropic. Positive change can also result from problems, difficulties, losses and challenges. However, while an overemphasis on either the positive or the negative aspect is dysfunctional, positive factors must be given extra emphasis for positivity to occur because negativity usually dominates (Cameron, 2008). One way to study positive functioning in organisations is to focus on positive practices.

Positive organisational practices produce positive individual behaviour, which, in turn, contributes to organisational effectiveness (Cameron, Mora, Leutscher, \& Calarco, 2011; Lyubomirsky, King, \& Diener, 2005). Cameron et al. (2011) categorise positive practices as caring, compassionate support, forgiveness, inspiration and meaning, as well as respect, integrity and gratitude. In pursuit of positive practices, organisations are also shifting their focus towards facilitating conditions to promote human flourishing (Cameron, 2010), for example, by attending to demands and resources individuals have, as well as their fit into their jobs and organisations. 
Work in organisations and experiences thereof are not always positive. For example, academic workers in higher education institutions experience work overload mainly because of long working hours and pressures of high volumes of quick work (Barkhuizen, Rothmann, \& Van de Vijver, 2014; Berg \& Seeber, 2016), precariousness, insecurity and ambiguity (Clark \& Sousa, 2018) and a lack of collegiality (Ryan, 2012). Job demands and a lack of resources associated with constant change result in disengagement and psychological unwellbeing of academic staff (Barkhuizen et al., 2014). A study by Mahomed and Rothmann (2019) showed that a significant percentage of academics in higher education institutions are not functioning optimally. However, focussing on positive practices even when the context and experiences thereof are negative might facilitate positive functioning of individuals and their institutions.

Research on positive practices in organisations is scarce. Researchers have studied the effects of positive practices on work engagement and performance (Geue, 2018), on organisational performance (Caza \& Cameron, 2008) and on organisational effectiveness (Cameron et al., 2011). In South Africa, only a few studies regarding positive practices have been conducted. Rautenbach (2015) found that positive emotions, support and inspiration were linked to the well-being of employees, while Redelinghuys, Rothmann and Botha (2018) showed that meaning, inspiration and support had an impact on workplace flourishing. Fouché (2015) found that meaning and inspiration affected the functioning of employees. The current study investigated how positive organisational practices were related to job demands and resources, person-environment fit (P-E fit) and well-being.

\section{Positive organisational practices}

Positive institutions can be defined as institutions that entertain a shared purpose and vision (of the moral goal of the institution), provide safety (protection against threats, danger and exploitation) and ensure fairness (equitable rules governing reward and punishment), humanity (care and concern) and dignity (treatment of all as individuals regardless of their position). Positive institutions are seen to be beneficial to individuals, institutions, communities and societies (Rothmann, 2014b).

According to Cameron et al. (2011), positivity in organisational science has three connotations. Firstly, the focus is on extraordinary positive outcomes or positively deviant performance, which means that results exceed expected performance (Spreitzer \& Sonenshein, 2003). Secondly, there is a focus on affirmative bias, or on strengths, capabilities and possibilities, rather than on problems, threats and weakness. In this area, literature takes a positive stance on climate, relationships, communication, meaning and energy in organisations (Baker, 2000; Cameron, 2008). Thirdly, the focus pertains to virtuousness and eudemonism (Cameron, Bright, \& Caza, 2004; Peterson \& Seligman, 2004). Virtuousness refers to instrumental exchange in relationships and focuses on the right thing to do with respect to the other, without intent of return (Peterson \& Seligman, 2004), while eudaimonia envisions that inclination exists in all human systems towards flourishing and the achievement of the highest aspirations (Cameron, 2011; Ryan \& Deci, 2001).

Research by Cameron et al. (2011) summarised six positive organisational practice dimensions: (1) caring (showing interest in, and responding to, one another and genuinely caring for one another as friends); (2) compassionate support (honouring and supporting one another in endeavours, building strong relationships through kindness and helping those who are struggling); (3) forgiveness (not placing the blame on one another for errors, but forgiving one another's mistakes); (4) inspiration (inspiring one another at work); (5) meaning (being motivated, renewed and elevated by work as employees see the purpose in work and discover its profound meaning); and (6) respect, integrity and gratitude (treating one another with respect, expressing appreciation, trusting one another and maintaining integrity).

No overarching theory was used to arrive at the mentioned list of positive practices. Such practices appeared in prior research, represent behavioural practices or activities, and possess at least one of the three connotations of positive deviance, virtuous practices and affirmative bias (Cameron et al., 2011). Positive practice dimensions can be seen as a description of the behaviours, practices and activities that reflect exceptional, affirmative and virtuous attitudes and actions of the organisation and its employees (Cameron et al., 2011). If positive practices are part of the organisational context, employees will experience increased positive affect and positive behaviour, which significantly contribute to profitability and performance in organisations (Cameron et al., 2011; Lyubomirsky et al., 2005).

\section{Positive practices and employee experiences}

Experiences of employees in relation to job demands and resources, P-E fit and well-being will be discussed in the next section.

\section{Job demands and resources}

Job demands represent aspects of the job that could potentially cause strain and can be defined as those physical, psychological, social or organisational aspects of a job that require sustained cognitive and emotional effort or skills and that are associated with physiological and psychological costs. Examples include work pressure and role ambiguity (Bakker, Demerouti, \& Sanz-Vergel, 2014; Demerouti \& Bakker, 2011). Job resources are those physical, psychological, social or organisational aspects of the job that are fundamental to achieve work goals, reduce job demands, diminish the associated physiological and psychological costs and stimulate personal growth, learning and development (Demerouti \& Bakker, 2011). 
The Job Demands-Resources (JD-R) model (Demerouti, Bakker, Nachreiner, \& Schaufeli, 2001) assumes that both job demands and job resources are present in work environments and could exhibit a positive (motivational) or a negative effect. Research on individual components of positive practices showed that caring relationships supported generativity, which assisted employees with the job resource of development and learning opportunity (Carmeli, Jones, \& Binyamin, 2016). Atkins and Parker (2012) found that compassion built the quality of relationships amongst organisational members, creating relational resources such as trust and strengthening shared values of interconnectedness (support) between co-workers. Madden, Duchon, Madden and Plowman (2012) showed that compassion influenced organisational members to have new resources at their disposal as well as new knowledge of what their roles entailed. Cox, Bennett, Tripp and Aquino (2012) found that forgiveness was relationship motivated, whereas nonforgiveness could be seen to place emotional demands on the employee. Research conducted by Zdaniuk and Bobocel (2015) revealed that workplace forgiveness could be influenced by leadership.

Bowling, Alarcon, Bragg and Hartman (2015) found that work overload had a negative impact on the inspiration of employees. Research conducted by De Gieter and Hofmans (2015) revealed that employees were inspired if they perceived the compensation (a job resource) they received as fair. Research furthermore showed that employees were inspired when they experienced clarity of roles, which enabled them to have a clear sense of purpose, to know what their organisation expects from them and to understand how their jobs fit into the environment (Barkhuizen et al., 2014; Panaccio \& Vanderberghe, 2011). Rothmann (2014a) reported that people could be inspired by advancement (a job resource), such as training and development opportunities, as well as potential future career progression. Studies (Deci \& Ryan, 2011; Harter \& Adkins, 2015; Rothmann, 2014a) also showed that employees were inspired by supportive supervisors (a job resource).

Research by Rothmann (2014a, 2015) showed that meaningful interpretations were generated through co-worker social support, which assisted employees in developing an understanding of their social reality and identity in an organisation. With relation to respect and gratitude, research showed that supervisor support included employee-oriented behaviours such as regular communication, accessibility, treating employees fairly and with respect, showing commitment to protecting employees' interests, being trustworthy and building genuine and trusting relationships with them (Harter \& Adkins, 2015; Kahn, 1990; Kahn \& Heaphy, 2014; Rothmann, 2014a). Liao and Weng (2018) found that gratefulness (gratitude) was a significant positive emotion that contributed to social connectedness and meaning in life.

\section{Person-environment fit}

Person-environment fit refers to the correspondence between internal aspects of the person (e.g. values, goals and abilities) and elements of the external environment (e.g. organisational values, culture, climate and goals) (Kristof-Brown \& Billsberry, 2013). This research focused on personorganisation fit (P-O fit) and person-job fit (P-J fit). The P-O fit is seen as the congruence between personal and organisational goals, norms and values ( $\mathrm{Su}$, Murdock, \& Rounds, 2015). If people experience this congruence, a perception of social inclusion and intention to stay emerges (Van Vianen, Stoelhorst, \& De Goede, 2013). The P-J fit emphasises the match between personal characteristics and job characteristics.

Regardless of the fit concept being considered, a good fit leads to beneficial outcomes for both the individual and the organisation (Gabriel, Diefendorff, Chandler, Moran, \& Greguras, 2014). When fit exists, employees typically report more favourable attitudes, perform more effectively and experience higher job tenure, enhanced job satisfaction, greater career success and improved well-being (Gabriel et al., 2014; Hoffman \& Woehr, 2006; Kristof-Brown, Zimmerman, \& Johnson, 2005; Su et al., 2015; Verquer, Beehr, \& Wagner, 2003).

Research on individual components of positive practices showed that caring relationships of top management teams enabled employees to connect more profoundly and to achieve desired objectives as a collective entity, which would result in P-O fit (Carmeli et al., 2016). Van Vianen et al. (2013) found that if employees experienced social inclusion (e.g. caring, support or respect), they would also experience the $\mathrm{P}-\mathrm{O}$ fit, where there was a congruence between personal goals and organisational goals. Research conducted by Kinman (2001), as well as Winter, Taylor and Sarros (2000), indicated that engaged employees obtained intrinsic motivation (inspiration) from their jobs and derived their identity from their work (job-fit).

\section{Well-being}

Well-being can be described as a state in which individuals feel well (i.e. emotional well-being [EWB]) and function well (i.e. psychological well-being [PWB] and social well-being [SWB]) (Keyes \& Annas, 2009).

In the South African context, Rothmann (2013) extended the Mental Health Continuum (MHC) of Keyes (2009) to the work context and found support for a model of well-being that included EWB (i.e. positive affect, negative affect and job satisfaction), PWB (i.e. autonomy, competence, relatedness, learning, meaningful work and engagement) and SWB (i.e. social acceptance, social growth, social contribution, social coherence and social integration).

\section{Aim of the study}

No research has examined the full spectrum of positive organisational practices in relation to employee experiences of job demands and resources, P-E fit and well-being. Scientific information regarding the experiences of employees 
and positive practices is needed to plan interventions and policies that will benefit individuals and organisations. Therefore, this study aimed to investigate how positive organisational practices relate to job demands and resources, P-E fit and well-being.

\section{Method}

\section{Participants and setting}

A total of 339 academic employees from three higher education institutions in South Africa participated in the study. The response rate was $23 \%(n=339)$. Table 1 shows the characteristics of the participants. Data in Table 1 represent employee-related characteristics of the participants: $56 \%$ of the respondents were Afrikaans speaking, $43.6 \%$ had a master's degree and $67.3 \%$ indicated that they had served more than 5 years in an academic profession. Most of the participants (91.4\%) were on levels ranging from junior lecturer to senior lecturer, and the majority of this group (50.9\%) were lecturers. Most of the participants were permanently appointed (85\%), were white South Africans (64.6\%) and were married (71.4\%). Male participants constituted $46.3 \%$ of the sample, while female participants constituted $53.7 \%$.

\section{Measuring instruments}

The Positive Practices Questionnaire (PPQ; Cameron et al., 2011), the Job Demands-Resources Scale (JDRS; Rothmann, Mostert, \& Strydom, 2006), two perceived fit scales from Greguras and Diefendorff (2009) and the Flourishing-at-Work

\begin{tabular}{|c|c|c|c|}
\hline Item & Category & Frequency & $\%$ \\
\hline \multirow[t]{2}{*}{ Gender } & Male & 157 & 46.3 \\
\hline & Female & 182 & 53.7 \\
\hline \multirow[t]{5}{*}{ Age } & $24-35$ years & 69 & 20.4 \\
\hline & $36-45$ years & 115 & 33.9 \\
\hline & $46-55$ years & 92 & 27.1 \\
\hline & $56-65$ years & 56 & 16.5 \\
\hline & $66-74$ years & 7 & 2.1 \\
\hline \multirow[t]{3}{*}{ Home language } & Afrikaans & 191 & 56.3 \\
\hline & English & 65 & 19.2 \\
\hline & African language & 83 & 24.5 \\
\hline \multirow[t]{6}{*}{ Highest qualification } & Diploma & 4 & 1.2 \\
\hline & Postgraduate diploma & 8 & 2.4 \\
\hline & Degree & 44 & 13.0 \\
\hline & Honours degree & 27 & 8.0 \\
\hline & Master's degree & 148 & 43.6 \\
\hline & Doctoral degree & 108 & 31.8 \\
\hline \multirow[t]{6}{*}{ Tenure } & Less than 5 years & 111 & 32.7 \\
\hline & $5-10$ years & 99 & 29.2 \\
\hline & $11-15$ years & 66 & 19.4 \\
\hline & $16-20$ years & 37 & 11.0 \\
\hline & $21-25$ years & 20 & 5.9 \\
\hline & More than 25 years & 6 & 1.8 \\
\hline \multirow[t]{5}{*}{ Position } & Junior lecturer & 54 & 15.9 \\
\hline & Lecturer & 172 & 50.7 \\
\hline & Senior lecturer & 84 & 24.8 \\
\hline & Professor or Associate professor & 12 & 3.6 \\
\hline & Head of department & 17 & 5.0 \\
\hline
\end{tabular}

Scale - Short Form (FAWS-SF; Rautenbach, 2015) were used in this study.

Questions from the PPQ (Cameron et al., 2011) were used to assess positive organisational practices in higher educational institutions. The survey consists of Likert-type items scored on a five-point scale, varying from 1 (strongly disagree) to 5 (strongly agree). Six dimensions constitute the PPQ: caring, compassionate support, forgiveness, inspiration, meaning, and respect, integrity and gratitude. All six dimensions were measured with three items: caring (e.g. 'we are interested in one another'), compassionate support (e.g. 'we help people who are facing difficulty'), forgiveness (e.g. 'we forgive mistakes'), inspiration (e.g. 'we inspire one another'), meaning (e.g. 'we are being renewed by what we do') and respect, integrity and gratitude (e.g. 'we treat one another with respect'). The items had the organisation as the analysis unit in mind, not the participant, as organisational qualities were assessed. In South Africa, Redelinghuys et al. (2018) established a Raykov's rho coefficient for the scales that varied between 0.90 and 0.96 .

Items from the JDRS (Rothmann et al., 2006) were administered to the participants. Respondents had to answer questions regarding the frequency with which they had experienced specific symptoms in the past one month. Workload was measured by three items (e.g. 'how often did you feel that you had too much work to do?'). Role clarity was also measured by three items (e.g. 'how often did you feel that you knew exactly what other people expected from you in your work?'). Three items measured remuneration (e.g. 'how often did you feel that your organisation paid good salaries?'). Advancement was measured by three items (e.g. 'how often did you feel that your company gave you opportunities to attend training courses aligned with your job?'). Co-worker support was measured by two items (e.g. 'how often did you feel that your co-workers valued your input?'). Each item required the respondents to answer on a scale ranging from 1 (never) to 6 (every day). Internal consistencies ranged from 0.76 to 0.92 , indicating an acceptable reliability.

Person-environment fit questions from two perceived fit scales from Greguras and Diefendorff (2009) were used. Three items of P-O fit (e.g. 'my personal values match my organisation's values and culture') and P-J fit (e.g. 'the match is very good between the demands of my job and my personal skills') measured how well employees perceived their abilities to fit these aspects. The reliability of these scales was between an $\alpha$ value of 0.82 and 0.88 . All the fit items were rated on a five-point scale ranging from 1 (not at all) to 5 (completely).

The FAWS-SF that was administered to the participants was derived from the FAWS (Rautenbach, 2015). It consists of 17 items that were chosen as the most archetypal items expressive of the construct definition of each of the three dimensions of well-being at work, namely, EWB, PWB and SWB. The participants had to answer questions regarding the 
frequency with which they had experienced specific symptoms during the past one month. Emotional well-being was measured by three items indicating two dimensions, namely, job satisfaction (e.g. 'how often did you experience satisfaction with your job?') and positive affect (e.g. 'how often did you feel happy?'). Psychological well-being was measured by nine items indicating autonomy (e.g. 'how often did you feel confident to think or express your own ideas and opinions?'), competence (e.g. 'how often did you feel good at managing the responsibilities of your job?'), relatedness (e.g. 'how often did you feel really connected with other people at your job?'), learning (e.g. 'how often did you find yourself learning?'), meaning (e.g. 'how often did you feel your work was meaningful?'), purpose (e.g. 'how often did you feel that the work you did served a greater purpose?'), cognitive engagement (e.g. 'how often did you find that when you were working, you were totally absorbed in your work?'), emotional engagement (e.g. 'how often did you get excited when you performed well on your job?') and physical engagement (e.g. 'how often did you feel energised when you worked?').

Social well-being was measured by means of five items indicating social contribution (e.g. 'how often did you feel that you had something important to contribute to your organisation?'), social acceptance (e.g. 'how often did you feel that you really belonged to your organisation?'), social growth (e.g. 'how often did you feel that your organisation was becoming a better place for people like you?'), social coherence (e.g. 'how often did you feel that people in your organisation were basically good?') and social integration (e.g. 'how often did you feel that the way your organisation worked made sense to you?'). Responses were measured on a six-point scale ranging from 1 (never) to 6 (every day), indicating the frequency with which respondents experienced each identified symptom of well-being. This response option allowed for the categorisation of levels of well-being similar to the three classes used to assess positive mental health (Keyes, 2002, 2005, 2007). The internal consistencies ranged from 0.82 to 0.90 , indicating acceptable reliabilities.

\section{Statistical analysis}

Latent profile analysis (LPA) was used to determine the number of profiles that fitted the data (Gabriel, Daniels, Diefendorff, \& Greguras, 2015). The Lo-Mendell-Rubin likelihood ratio test (LMR LR) (Lo, Mendell, \& Rubin, 2001), the Adapted Lo-Mendell-Rubin (ALMR) likelihood ratio test and the significant bootstrap likelihood ratio test (BLRT) were used to assess the fit between two models that differed by one class and provided a $p$-value indicating the best-fitting model. The sample-size-adjusted Bayesian information criterion (ABIC) was also used to assess the model fit (NylundGibson, Asparouhov, \& Muthén, 2007). Lastly, entropy was investigated to provide an index of model classification quality. Values greater than 0.80 indicated adequate classification quality, and values closer to 1.0indicated better classification quality (Jung \& Wickrama, 2008).
Measurement models of distal variables were tested using confirmatory factor analysis (CFA) in Mplus 8.3 (Muthén \& Muthén, 1998-2019). The maximum likelihood with robust standard errors (MLR) estimator was used. Model fit was assessed using the following fit indices: the chi-square statistic (the test of absolute fit of the model), standardised root mean residual (SRMR), root mean square error of approximation (RMSEA), Tucker-Lewis index (TLI) and comparative fit index (CFI) (West, Taylor, \& Wu, 2012). For TLI and CFI values to be acceptable, scores higher than 0.90 were required, while values larger than 0.95 indicated an excellent fit. Both RMSEA and SRMR values lower than 0.08 indicated a close fit between the model and the data.

Descriptive statistics were computed using the SPSS 25.0 program (IBM Corp., 2017). These statistics were calculated to describe the data, and Pearson's correlation coefficients were used to investigate the relationships between the variables. Point estimates of scale reliability were computed using CFA (see Raykov, 2009). A cut-off value of 0.70 for scale reliability (Raykov, 2009) was used.

\section{Research procedure}

The researcher administered the online electronic questionnaire in English via the myresearchsurvey.com platform. The questionnaire was accompanied by a cover letter explaining the purpose of the study and emphasising the confidentiality and anonymity of the research project. Participation in the project was voluntary and respondents had the option to withdraw from the study at any time. The participants completed an online questionnaire from the end of August until mid-October 2015. An Excel spreadsheet was used to capture the responses to the items and was then converted into an SPSS data set for analysis.

\section{Ethical consideration}

Ethical approval to conduct the study was obtained from the North-West University (clearance number: NWUHS-2014-0126).

\section{Results}

\section{Latent profile analysis}

Latent profile analysis with Mplus 8.3 (Muthén \& Muthén, 1998-2019) was carried out on group participants based on their responses to items that assessed positive organisational practices. Different models with an increasing number of latent profiles were tested. Significant enhancement from the reference model to the model with the most profiles led to a model being retained. Models were compared using the lowest Bayesian information criterion (BIC) value and entropy values ranging from 0 to 1 , where higher values were better. (Values smaller than 0.60 were not accepted.) The LMR LR test (Lo et al., 2001), the adjusted LMR LR test and the BLRT (Wang \& Wang, 2012) were used in Mplus to test the number of profiles in a mixture analysis. Posterior class membership probabilities as well as entropy values were used to specify the quality of class membership. 
To determine the LPA model, several steps were followed. The first step included determining the ideal number of latent profiles. In the second step, an investigation of the latent profile classification was done. The third step included labelling the latent profiles. The prediction of latent profile membership was completed in the fourth step. To determine the number of latent profiles, four models with different numbers of latent profiles were estimated and compared, starting with a single-class model and increasing the number of profiles by 1 at a time. The fit indices are reported in Table 2. The Akaike information criterion (AIC) (16 726.16), the BIC (16 863.89) and the sample-size-adjusted BIC (ABIC) (16 749.69) values of the model with one latent class were the largest, indicating that this model had the worst fit.

Next, the quality of the latent profile membership was investigated. The entropy values for the two-profile and fourprofile LPA were 0.83 and 0.97 , respectively, indicating a good classification (Clark, 2010). The posterior probabilities for the most likely latent profile membership were 0.97 (Profile 1), 0.99 (Profile 2), 0.99 (Profile 3) and 0.98 (Profile 4). The classes were labelled based on their means on the 18 questions (see Figure 1 and Table 3 ).

The scale that was used to obtain responses from the participants had five points: disagree strongly (1), disagree (2), undecided (3), agree (4) and agree strongly (5). Profile 1 comprised $11.8 \%$ of the sample and Profile 2 constituted $26.25 \%$ of the sample. Profile 3 consisted of $53.1 \%$ of the sample, while Profile 4 comprised $8.85 \%$ of the sample.

TABLE 2: Comparison of different latent profile analysis models.

\begin{tabular}{lcccccc}
\hline Model & AIC & BIC & ABIC & $\begin{array}{c}\text { LMR LR test } \\
\boldsymbol{p} \text {-value }\end{array}$ & $\begin{array}{c}\text { ALMR LR test } \\
\boldsymbol{p} \text {-value }\end{array}$ & $\begin{array}{c}\text { BLRT } \\
\boldsymbol{p} \text {-value }\end{array}$ \\
\hline 1-class & 16726.16 & 16863.89 & 16749.69 & - & - & - \\
2-class & 14189.70 & 14391.13 & 14216.66 & 0.228 & 0.230 & $0.000^{*}$ \\
3-class & 13241.92 & 13525.05 & 13290.31 & 0.240 & 0.240 & $0.000^{*}$ \\
4-class & 12562.94 & 12918.76 & 12623.75 & 0.090 & 0.090 & $0.000^{*}$ \\
5-class & 12352.00 & 12780.52 & 12425.23 & 0.387 & 0.392 & $0.000^{*}$ \\
\hline
\end{tabular}

ALMR LR, Adapted Lo-Mendell-Rubin likelihood ratio; ABIC, adjusted Bayesian information criterion; AIC, Akaike information criterion; BIC, Bayesian information criterion; BLRT, bootstrap likelihood ratio test; LMR, Lo-Mendell-Rubin.

$*, p<0.01$.

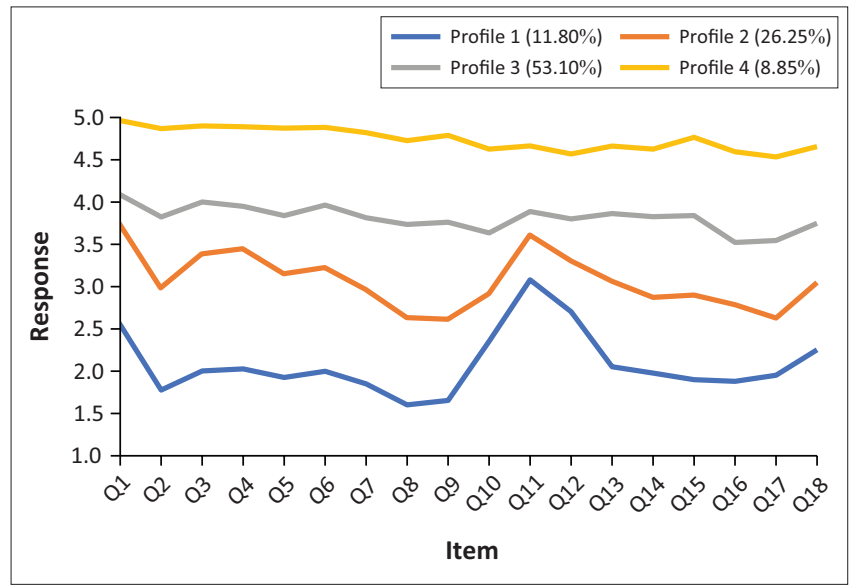

Q, question.

FIGURE 1: The four latent profiles.
The characteristics of the four positive practice profiles are discussed next.

\section{Profile 1 - Absence of virtuous organisational practices $(\mathbf{1 1 . 8 0 \% )}$}

The individuals in Profile 1 indicated a lack of positive practices in their organisational setting. They showed their disagreement on experiences of trust (Q2), gratitude (Q3), helping people who were facing difficulty (Q4), providing emotional support to one another (Q5), honouring one another's talents (Q6), being interested in one another (Q7), sharing enthusiasm with one another (Q13), inspiring one another (Q14), communicating the good they saw in one another (Q15), not blaming one another when mistakes were made (Q16), correcting errors without placing the blame on one another (Q17) and forgiving mistakes (Q18). Individuals experienced higher levels of disagreement on thinking of one another as friends (Q8) and genuinely caring about one another (Q9). Disagreement was also evident on items such as treating one another with respect (Q1), being renewed by work (Q10) and finding the work motivating (Q12), while indecisiveness was shown regarding feeling that their work had profound meaning (Q11).

\section{Profile 2 - Indecisiveness regarding virtuous practices $(26.25 \%)$}

In this profile, there was agreement that individuals treated one another with respect (Q1) and felt that their work had profound meaning (Q11). However, employees were indecisive about whether they trusted one another $(\mathrm{Q} 2)$, whether they were interested in one another (Q7), whether they were renewed by what they did (Q10), whether they shared enthusiasm with one another (Q13) and whether they forgave mistakes (Q18). Lower levels of agreement were felt towards the expression of gratitude (Q3), whether they helped people who were facing difficulty (Q4), whether they provided emotional support to one another (Q5), whether they honoured one another's talents (Q6) and whether they found their work motivating (Q12). Lower levels of

TABLE 3: Items of the Positive Practices Questionnaire.

\begin{tabular}{|c|c|}
\hline Dimension & Item \\
\hline \multirow{3}{*}{$\begin{array}{l}\text { Dignity and } \\
\text { respect }\end{array}$} & We treat one another with respect (1) \\
\hline & We trust one another (2) \\
\hline & We express gratitude to one another ( 3 ) \\
\hline \multirow[t]{3}{*}{ Support } & We help people who are facing difficulty (4) \\
\hline & We provide emotional support to one another (5) \\
\hline & We honour one another's talents (6) \\
\hline \multirow[t]{3}{*}{ Caring } & We are interested in one another (7) \\
\hline & We think of one another as friends ( 8 ) \\
\hline & We genuinely care about one another (9) \\
\hline \multirow[t]{3}{*}{ Meaning } & We are being renewed by what we do (10) \\
\hline & We feel that our work has profound meaning (11) \\
\hline & We find our work motivating (12) \\
\hline \multirow[t]{3}{*}{ Inspiration } & We share enthusiasm with one another (13) \\
\hline & We inspire one another (14) \\
\hline & We communicate the good we see in one another (15) \\
\hline \multirow[t]{3}{*}{ Forgiveness } & We do not blame one another when mistakes are made (16) \\
\hline & We correct errors without placing the blame on one another (17) \\
\hline & We forgive mistakes (18) \\
\hline
\end{tabular}


disagreement showed that individuals did not experience the following aspects in their environment: thinking of one another as friends (Q8), genuinely caring about one another (Q9), inspiring one another (Q14), communicating the good they saw in one another (Q15), not blaming one another when mistakes were made (Q16) and correcting errors without placing the blame on one another (Q17).

\section{Profile 3 - Presence of most positive organisational practices $\mathbf{( 5 3 . 1 0 \% )}$}

Employees in this profile agreed that there were positive practices in their work context, which included respect (Q1), trust $(\mathrm{Q} 2)$, gratitude $(\mathrm{Q} 3)$, compassionate support (Q4, Q5 and Q6), caring (Q7, Q8 and Q9), meaning and motivation in their work setting (Q11 and Q12), inspiration (Q13, Q14 and Q15) and forgiveness of mistakes (Q18). Only a few aspects showed lower levels of agreement: being renewed by what they did (Q10), not blaming one another when mistakes were made (Q16) and correcting errors without placing the blame on one another (Q17).

\section{Profile 4 - Strong positive organisational practices $(8.85 \%)$}

Individuals in this profile strongly agreed on experiencing positive practices in their work environment. They felt respected $(\mathrm{Q} 1)$, trusted $(\mathrm{Q} 2)$, grateful $(\mathrm{Q} 3)$ and inspired (Q13, Q14 and Q15). A strong agreement was also reached on social aspects, such as support (Q4, Q5 and Q6), caring (Q7, Q8 and Q9) and forgiveness (Q16, Q17 and Q18). Furthermore, they attained meaning and motivation in their work (Q10, Q11 and Q12).

\section{Confirmatory factor analysis}

To check whether items of the different scales (JDRS, P-E fit scale and FAWS-SF) loaded onto the factors on which they were supposed to load, CFA was used. The measurement model showed an acceptable fit $\left(\Sigma_{(580, N=272)}^{2}=1110.09, p<0.0001\right.$; $\mathrm{CFI}=0.91$; TLI $=0.90 ;$ RMSEA $=0.05[0.04,0.05, p=0.0243]$; SRMR $=0.07)$. Inspecting the loadings, the overall size of the factor loadings was acceptable (overload: $\lambda=0.78-0.91$, mean $=$ 0.85 ; role clarity: $\lambda=0.51-0.82$, mean $=0.62$; training and development: $\lambda=0.57-0.97$, mean $=0.75$; co-worker relations: $\lambda=0.75-0.91$, mean $=0.83$; supervisor relations: $\lambda=0.75-0.83$, mean $=0.78 ; \mathrm{P}-\mathrm{E}$ fit: $\lambda=0.79-0.86$, mean $=0.83 ; \mathrm{P}-\mathrm{J}$ fit: $\lambda=0.56-0.97$, mean $=0.78 ;$ EWB: $\lambda=0.68-0.87$, mean $=0.77 ; \mathrm{PWB}: \lambda=0.58-0.80$, mean $=0.70$; SWB: $\lambda=0.52-0.86$, mean $=0.76$ ).

\section{Descriptive statistics}

The descriptive statistics (means and standard deviations), point estimate reliabilities and Pearson's correlations are presented in Table 4.

Table 4 shows that the point estimate reliability coefficients of most of the scales were higher than 0.70 , indicating an acceptable internal consistency (Nunnally \& Bernstein, 1994).

As shown in Table 4, job resources (i.e. role clarity, training and development, co-worker relations and supervisor support) were statistically significantly (practically significant, medium effect) and positively related to P-O fit. Job resources had a statistically significant effect on P-J fit, but the practical significance was small. Job resources were also statistically significantly (practically significant, medium effect) and positively related to all well-being components (i.e. EWB, PWB and SWB). Hence, job resources were associated with fit and well-being.

The P-O fit had a statistically significant effect on all the dimensions of well-being, but showed the strongest correlation towards SWB. The P-J fit had a smaller statistically significant effect on EWB and SWB, but a medium statistically significant effect on PWB.

\section{Latent profiles and distal outcomes}

The differences between the distal outcome scores of different latent profiles were investigated using the automatic Bolck, Croon and Hagenaars (BCH) approach (Wang \& Wang, 2012) for estimating the mean of a distal continuous outcome across latent profiles (Asparouhov \& Muthén, 2014; Bakk \& Vermunt, 2016). The latent profile model was estimated using the indicator variables of the PPQ. The means of the auxiliary variables were estimated across the different profiles using the $\mathrm{BCH}$ method to avoid shifts in determining the LPA. The $\mathrm{BCH}$ method uses weighted multiple-group analysis to identify where the groups correspond to the latent profiles, and a shift in the classes is not possible because the profiles

TABLE 4: Descriptive statistics, reliability coefficients and correlations of the scales.

\begin{tabular}{|c|c|c|c|c|c|c|c|c|c|c|c|c|}
\hline Item & Mean & SD & $\rho$ & 1 & 2 & 3 & 4 & 5 & 6 & 7 & 8 & 9 \\
\hline Overload & 3.68 & 1.29 & 0.88 & - & - & - & - & - & - & - & - & - \\
\hline Role clarity & 4.46 & 1.11 & 0.74 & -0.06 & - & - & - & - & - & - & - & - \\
\hline Training and development & 3.12 & 1.38 & 0.81 & -0.10 & $0.34 * \dagger$ & - & - & - & - & - & - & - \\
\hline Co-worker relations & 4.21 & 1.22 & 0.82 & -0.04 & $0.59 * \div$ & $0.36 * \dagger$ & - & - & - & - & - & - \\
\hline Supervisor relations & 3.46 & 1.01 & 0.82 & -0.07 & $0.69 * \div$ & $0.51 *$ & $0.41 * \dagger$ & - & - & - & - & - \\
\hline P-O fit & 2.98 & 0.91 & 0.87 & -0.07 & $0.40 * \dagger$ & $0.47^{* \dagger}$ & $0.48 * \dagger$ & $0.38 * \dagger$ & - & - & - & - \\
\hline P-J fit & 4.09 & 0.69 & 0.83 & 0.06 & $0.24^{*}$ & $0.14^{*}$ & $0.33 * \dagger$ & $0.19 *$ & $0.21 *$ & - & - & - \\
\hline EWB & 3.98 & 6.12 & 0.82 & -0.03 & $0.49 * \dagger$ & $0.39 * \dagger$ & $0.47 * \dagger$ & $0.41 * \dagger$ & $0.51 * \star$ & $0.27^{*}$ & - & - \\
\hline PWB & 4.17 & 1.08 & 0.90 & 0.02 & $0.59 * \ddagger$ & $0.37 * \dagger$ & $0.58 * \vdots$ & $0.37 * \dagger$ & $0.57 * \star$ & $0.40 * \dagger$ & $0.93 * \ddagger$ & - \\
\hline SWB & 3.63 & 1.19 & 0.82 & -0.10 & $0.57 *+$ & $0.53 *+$ & $0.56 * \dagger$ & $0.50 *+$ & $0.74 *+$ & $0.24 *$ & $0.81 * \dagger$ & $0.81 *$ \\
\hline
\end{tabular}

EWB, emotional well-being; SWB, social well-being; PWB, psychological well-being; P-O fit, person-organisation fit; P-J fit, person-job fit; SD, standard deviation.

$*, p<0.05$ - statistically significant.

$\dagger, r>0.30$ - practically significant (medium effect); $\ddagger, r>0.50$ - practically significant (large effect). 
TABLE 5: Equality tests of means across profiles: Job demands and resources, person-environment fit and well-being.

\begin{tabular}{|c|c|c|c|c|c|}
\hline Variable & Profile & Mean & SE & $\chi^{2}$ & $p$ \\
\hline \multirow[t]{11}{*}{ Overload } & Profile 1 & 0.43 & 0.18 & - & - \\
\hline & Profile 2 & 0.05 & 0.12 & - & - \\
\hline & Profile 3 & -0.18 & 0.08 & - & - \\
\hline & Profile 4 & 0.33 & 0.17 & - & - \\
\hline & Overall test & - & - & 14.18 & $0.00 * *$ \\
\hline & Profile 2 versus 3 & - & - & 2.35 & 0.13 \\
\hline & Profile 1 versus 3 & - & - & 9.46 & $0.00 * *$ \\
\hline & Profile 3 versus 4 & - & - & 7.02 & $0.01 * *$ \\
\hline & Profile 1 versus 2 & - & - & 3.15 & 0.08 \\
\hline & Profile 2 versus 4 & - & - & 1.83 & 0.18 \\
\hline & Profile 1 versus 4 & - & - & 0.16 & 0.69 \\
\hline \multirow[t]{11}{*}{ Role clarity } & Profile 1 & -0.54 & 0.09 & - & - \\
\hline & Profile 2 & -0.18 & 0.06 & - & - \\
\hline & Profile 3 & 0.13 & 0.03 & - & - \\
\hline & Profile 4 & 0.5 & 0.1 & - & - \\
\hline & Overall test & - & - & 84.92 & $0.00 * *$ \\
\hline & Profile 2 versus 3 & - & - & 21.54 & $0.00 * *$ \\
\hline & Profile 1 versus 3 & - & - & 47.18 & $0.00 * *$ \\
\hline & Profile 3 versus 4 & - & - & 13.13 & $0.00 * *$ \\
\hline & Profile 1 versus 2 & - & - & 11.32 & $0.00 * *$ \\
\hline & Profile 2 versus 4 & - & - & 36.86 & $0.00 * *$ \\
\hline & Profile 1 versus 4 & - & - & 61.04 & $0.00 * *$ \\
\hline \multirow{11}{*}{$\begin{array}{l}\text { Co-worker } \\
\text { support }\end{array}$} & Profile 1 & -1.28 & 0.18 & - & - \\
\hline & Profile 2 & -0.43 & 0.12 & - & - \\
\hline & Profile 3 & 0.33 & 0.07 & - & - \\
\hline & Profile 4 & 1.04 & 0.2 & - & - \\
\hline & Overall test & - & - & 112.91 & $0.00 * *$ \\
\hline & Profile 1 versus 2 & - & - & 30.5 & $0.00 * *$ \\
\hline & Profile 2 versus 3 & - & - & 70.13 & $0.00 * *$ \\
\hline & Profile 2 versus 4 & - & - & 11.57 & $0.00 * *$ \\
\hline & Profile 1 versus 3 & - & - & 15.13 & $0.00 * *$ \\
\hline & Profile 1 versus 4 & - & - & 40.86 & $0.00 * *$ \\
\hline & Profile 3 versus 4 & - & - & 75.13 & $0.00 * *$ \\
\hline \multirow{11}{*}{$\begin{array}{l}\text { Training and } \\
\text { development }\end{array}$} & Profile 1 & -0.57 & 0.11 & - & - \\
\hline & Profile 2 & -0.22 & 0.08 & - & - \\
\hline & Profile 3 & 0.12 & 0.07 & - & - \\
\hline & Profile 4 & 0.73 & 0.18 & - & - \\
\hline & Overall test & - & - & 52.88 & $0.00 * *$ \\
\hline & Profile 2 versus 3 & - & - & 9.79 & $0.00 * *$ \\
\hline & Profile 1 versus 3 & - & - & 30.15 & $0.00 * *$ \\
\hline & Profile 3 versus 4 & - & - & 9.96 & $0.00 * *$ \\
\hline & Profile 1 versus 2 & - & - & 6.6 & $0.01 * *$ \\
\hline & Profile 2 versus 4 & - & - & 22.6 & $0.00 * *$ \\
\hline & Profile 1 versus 4 & - & - & 38.13 & $0.00 * *$ \\
\hline \multirow{11}{*}{$\begin{array}{l}\text { Supervisor } \\
\text { relations }\end{array}$} & Profile 1 & -0.57 & 0.11 & - & - \\
\hline & Profile 2 & -0.22 & 0.08 & - & - \\
\hline & Profile 3 & 0.12 & 0.07 & - & - \\
\hline & Profile 4 & 0.73 & 0.18 & - & - \\
\hline & Overall & - & - & 102.44 & $0.00 * *$ \\
\hline & Profile 2 versus 3 & - & - & 22.64 & $0.00 * *$ \\
\hline & Profile 1 versus 3 & - & - & 40.49 & $0.00 * *$ \\
\hline & Profile 3 versus 4 & - & - & 24.81 & $0.00 * *$ \\
\hline & Profile 1 versus 2 & - & - & 7.23 & $0.01 * *$ \\
\hline & Profile 2 versus 4 & - & - & 61.71 & $0.00 * *$ \\
\hline & Profile 1 versus 4 & - & - & 77.64 & $0.00 * *$ \\
\hline
\end{tabular}

Table 5 continues
TABLE 5 (Continues...): Equality tests of means across profiles: Job demands and resources, person-environment fit and well-being.

\begin{tabular}{|c|c|c|c|c|c|}
\hline Variable & Profile & Mean & SE & $\chi^{2}$ & $p$ \\
\hline \multirow[t]{11}{*}{ Person-job fit } & Profile 1 & -0.02 & 0.08 & - & - \\
\hline & Profile 2 & -0.01 & 0.05 & - & - \\
\hline & Profile 3 & -0.01 & 0.03 & - & - \\
\hline & Profile 4 & 0.11 & 0.1 & - & - \\
\hline & Overall test & - & - & 1.43 & 0.7 \\
\hline & Profile 2 versus 3 & - & - & 0.01 & 0.92 \\
\hline & Profile 1 versus 3 & - & - & 0.04 & 0.84 \\
\hline & Profile 3 versus 4 & - & - & 1.24 & 0.27 \\
\hline & Profile 1 versus 2 & - & - & 0.02 & 0.9 \\
\hline & Profile 2 versus 4 & - & - & 1.26 & 0.26 \\
\hline & Profile 1 versus 4 & - & - & 1.11 & 0.29 \\
\hline \multirow{11}{*}{$\begin{array}{l}\text { Emotional } \\
\text { well-being }\end{array}$} & Profile 1 & -0.58 & 0.15 & - & - \\
\hline & Profile 2 & -0.27 & 0.1 & - & - \\
\hline & Profile 3 & 0.17 & 0.06 & - & - \\
\hline & Profile 4 & 0.59 & 0.19 & - & - \\
\hline & Overall test & - & - & 40.13 & $0.00 * *$ \\
\hline & Profile 2 versus 3 & - & - & 15.11 & $0.00 * *$ \\
\hline & Profile 1 versus 3 & - & - & 21.58 & $0.00 * *$ \\
\hline & Profile 3 versus 4 & - & - & 4.22 & $0.04 *$ \\
\hline & Profile 1 versus 2 & - & - & 2.99 & 0.08 \\
\hline & Profile 2 versus 4 & - & - & 15.64 & $0.00 * *$ \\
\hline & Profile 1 versus 4 & - & - & 22.45 & $0.00 * *$ \\
\hline \multirow[t]{11}{*}{ Social well-being } & Profile 1 & -0.28 & 0.07 & - & - \\
\hline & Profile 2 & -0.59 & 0.09 & - & - \\
\hline & Profile 3 & 0.18 & 0.04 & - & - \\
\hline & Profile 4 & 0.57 & 0.14 & - & - \\
\hline & Overall test & - & - & 97 & $0.00 * *$ \\
\hline & Profile 2 versus 3 & - & - & 34.58 & $0.00 * *$ \\
\hline & Profile 1 versus 3 & - & - & 59.46 & $0.00 * *$ \\
\hline & Profile 3 versus 4 & - & - & 7.59 & $0.01 * *$ \\
\hline & Profile 1 versus 2 & - & - & 7.83 & $0.01 * *$ \\
\hline & Profile 2 versus 4 & - & - & 32.34 & $0.00 * *$ \\
\hline & Profile 1 versus 4 & - & - & 51.11 & $0.00 * *$ \\
\hline \multirow{11}{*}{$\begin{array}{l}\text { Person- } \\
\text { organisation fit }\end{array}$} & Profile 1 & -0.76 & 0.12 & - & - \\
\hline & Profile 2 & -0.31 & 0.09 & - & - \\
\hline & Profile 3 & 0.21 & 0.05 & - & - \\
\hline & Profile 4 & 0.71 & 0.15 & - & - \\
\hline & Overall test & - & - & 90.94 & $0.00 * *$ \\
\hline & Profile 2 versus 3 & - & - & 26.4 & $0.00 * *$ \\
\hline & Profile 1 versus 3 & - & - & 54.19 & $0.00 * *$ \\
\hline & Profile 3 versus 4 & - & - & 9.84 & $0.00 * *$ \\
\hline & Profile 1 versus 2 & - & - & 9.25 & $0.00 * *$ \\
\hline & Profile 2 versus 4 & - & - & 35.27 & $0.00 * *$ \\
\hline & Profile 1 versus 4 & - & - & 58.55 & $0.00 * *$ \\
\hline \multirow{11}{*}{$\begin{array}{l}\text { Psychological } \\
\text { well-being }\end{array}$} & Profile 1 & -0.75 & 0.18 & - & - \\
\hline & Profile 2 & -0.31 & 0.11 & - & - \\
\hline & Profile 3 & 0.2 & 0.07 & - & - \\
\hline & Profile 4 & 0.78 & 0.23 & - & - \\
\hline & Overall test & - & - & 45.23 & $0.00 * *$ \\
\hline & Profile 1 versus 3 & - & - & 15.22 & $0.00 * *$ \\
\hline & Profile 2 versus 3 & - & - & 24.51 & $0.00 * *$ \\
\hline & Profile 3 versus 4 & - & - & 5.83 & $0.02 * *$ \\
\hline & Profile 1 versus 2 & - & - & 4.2 & $0.04 *$ \\
\hline & Profile 1 versus 4 & - & - & 18.15 & $0.00 * *$ \\
\hline & Profile 2 versus 4 & - & - & 27.23 & $0.00 * *$ \\
\hline
\end{tabular}

$\mathrm{SE}$, standard error.

$*, p<0.05 ; * *, p<0.01$. 


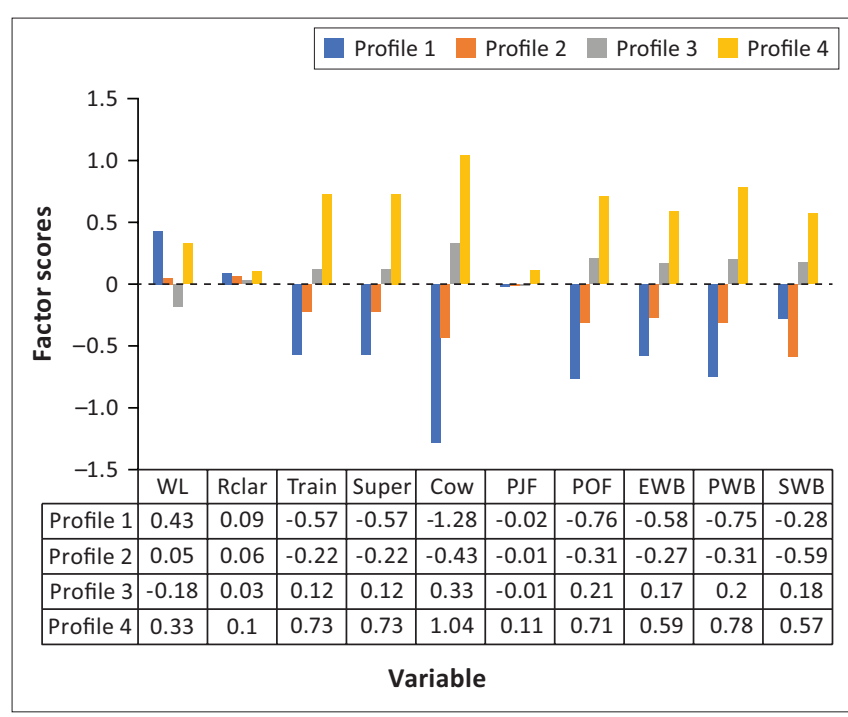

WL, overload; RClar, role clarity; Train, training and development; Super, supervisor relations; Cow, co-worker support; PJF, person-job fit; POT, person-organisation fit; EWB, emotional well-being; PWB, psychological well-being; SWB, social well-being.

FIGURE 2: The differences between distal variable scores of latent profiles.

are known (Asparouhov \& Muthén, 2014). Results using the $\mathrm{BCH}$ method are presented in Table 5.

The results in Table 5 show that statistically significant differences existed between the overload $\left(\chi^{2}=14.18\right.$, $p<0.001)$, role clarity $\left(\chi^{2}=84.92, p<0.001\right)$, training and development $\left(\chi^{2}=52.88, p<0.001\right)$, co-worker support $\left(\chi^{2}=112.91, p<0.001\right)$, supervisor relations $\left(\chi^{2}=102.44\right.$, $p<0.001)$, P-O fit $\left(\chi^{2}=45.23, p<0.001\right)$, EWB $\left(\chi^{2}=40.13\right.$, $p<0.001), \operatorname{PWB}\left(\chi^{2}=45.23, p<0.001\right)$ and SWB $\left(\chi^{2}=97.00, p<\right.$ $0.001)$ of different organisational practices profiles.

Figure 2 shows that individuals who experienced a lack of positive practices in their institutions reported significantly more overload compared to those who experienced strong virtuous practices. They also reported less role clarity, training and development, co-worker support, supervisor support, $\mathrm{P}-\mathrm{O}$ fit, and EWB, PWB and SWB compared to all other profiles. Individuals who were indecisive regarding the existence of positive practices in their institutions experienced less role clarity, training and development, co-worker support, supervisor support, P-O fit, and EWB, PWB and SWB compared to profiles 3 and 4. Participants in Profile 3 experienced not only statistically significantly less overload but also less role clarity, training and development, co-worker support, supervisor support, P-O fit, and EWB, PWB and SWB compared to Profile 4.

\section{Discussion}

This study aimed to investigate how positive organisational practices related to job demands and resources, P-E fit and well-being. The results showed that four profiles could be extracted, namely, absence of positive organisational practices (Profile 1), indecisiveness about the presence of positive organisational practices (Profile 2), presence of most positive organisational practices (Profile 3 ) and strong positive organisational practices (Profile 4). Statistically significant differences were found between the experiences of job demands and resources, P-E fit and well-being of the four profiles.
Individuals in Profile 1 (representing $11.8 \%$ of the total sample) indicated a lack of positive practices, and especially respect, support, caring, inspiration and forgiveness in their institutions. The only practice that measured somewhat higher was meaning (specifically in the jobs of individuals). Individuals who experienced a lack of positive practices in their institutions reported significantly more overload compared to those who experienced strong virtuous practices. They also reported less role clarity, training and development, co-worker support, supervisor support, P-O fit, and EWB, PWB and SWB compared to all other profiles.

Individuals in Profile 2 (representing 26.25\% of the total sample) were indecisive regarding the presence of positive practices in their jobs. These individuals agreed that people in their institutions treated one another with respect and that their work had meaning. However, they were indecisive regarding the levels of support, inspiration and forgiveness. Furthermore, they reported a lack of caring in their institutions. Individuals who were indecisive regarding the existence of positive practices in their institutions experienced less role clarity, training and development, co-worker support, supervisor support, P-O fit, and EWB, PWB and SWB compared to profiles 3 and 4.

Profile 3 (representing $53.1 \%$ of the total sample) included individuals who agreed that most of the six positive practices were evident in their institutions. They were indecisive regarding aspects of two dimensions, namely, meaning and forgiveness. Participants in Profile 3 experienced not only statistically significantly less overload but also less role clarity, training and development, co-worker support, supervisor support, P-O fit, and EWB, PWB and SWB compared to those in Profile 4. Profile 4 (representing 8.85\% of the total sample) included individuals who reported strong positive practices in their institutions.

The results of this study confirmed that positive organisations (as indicated by the presence of positive practices) mattered for academics' experiences of job demands and resources, P-E fit, as well as their optimal functioning. A lack of positive practices was related to experiences of overload, poor role clarity, insufficient training and development, poor co-worker and supervisor support, lack of $\mathrm{P}-\mathrm{O}$ fit, and poor EWB, PWB and SWB. Individuals who were indecisive regarding the existence of positive practices in their institutions also experienced less role clarity, training and development, co-worker support, supervisor support, P-O fit, and EWB, PWB and SWB. Academics who perceived positive organisational practices in their institutions experienced less overload, more role clarity, better training and development opportunities, higher co-worker and supervisor support, P-O fit, and EWB, PWB and SWB.

It is encouraging that more than $60 \%$ of the academics in this study reported moderate to high levels of positive organisational practices. More than $38 \%$ of the academics either experienced low levels of positive practices or were 
indecisive whether such practices exist in their institutions. However, even in these profiles, meaning, as well as treating people with respect, showed higher scores than other positive practices. Although these academics experienced higher job demands, lower job resources, less P-E fit and higher unwell-being, respect and meaning can be regarded as a starting point for institutional change.

Therefore, positive organisational practices, such as respect, support, meaning, caring, inspiration and forgiveness, matter for experiences of job demands and resources, perceptions of $\mathrm{P}-\mathrm{O}$ fit and the flourishing of academics. Academic leaders could create positive institutions by connecting employees to their purpose, nurturing authentic conversations, seeing latent potential and building belief in the reality of possibility, moving people from the natural pursuit of self-interest to the unnatural pursuit of the common good and by building trust that positive practices will spread through an institution (Quinn, 2015).

\section{Limitations and recommendations}

This study had various limitations. Firstly, a cross-sectional design was used, which implies that the causality of relationships could not be tested. Common method variance perceives a relationship between variables that can be attributed to certain factors other than the intended constructs, although a cross-sectional design can be used for establishing covariance, chronological procedure, ruling out of alternatives and establishing an explanatory mechanism (Spector, 2019). Secondly, it was impossible to use a random sampling in this study. Therefore, the findings cannot be generalised to all higher educational institutions in South Africa. Thirdly, common method variance could limit the value of the findings of this study.

\section{Conclusion}

This study provides support for the associations of virtuous practices in positive institutions with employee experiences of job demands and resources, P-E fit and flourishing or languishing of staff members.

\section{Acknowledgements Competing interests}

The authors have declared that no competing interests exist.

\section{Author's contributions}

Both authors contributed equally to this article.

\section{Funding information}

This research received no specific grant from any funding agency in the public, commercial or not-for-profit sectors.

\section{Data availability statement}

Data sharing is not applicable to this article as no new data were created or analyses in this study.

\section{Disclaimer}

The views and opinions expressed in this article are those of the authors and do not necessarily reflect the official policy or position of any affiliated agency of the authors.

\section{References}

Asparouhov, T., \& Muthén, B. (2014). Auxiliary variables in mixture modeling: Using the $\mathrm{BCH}$ method in Mplus to estimate a distal outcome model and an arbitrary secondary model. Mplus Web Notes, 21(2), 1-22. https://doi.org/10.1080/10705 511.2014.915181

Atkins, P.W.B., \& Parker, S.K. (2012). Understanding individual compassion in organizations: The role of appraisals and psychological flexibility. Academy of Management Review, 37(4), 524-546. https://doi.org/10.5465/amr.2010.0490

Baker, W. (2000). Achieving success through social capital. San Francisco, CA: Jossey-Bass.

Bakker, A.B., Demerouti, E., \& Sanz-Vergel, A.I. (2014). Burnout and work engagement: The JD-R approach. Annual Reviews in Organizational Psychology and Organizational Behavior, 1(1), 389-411. https://doi.org/10.1146/annurevorgpsych-031413-091235

Bakk, Z., \& Vermunt, K.K. (2016). Robustness of stepwise latent class modeling with continuous distal outcomes. Structural Equation Modeling: A Multidisciplinary Journal, 23(1), 20-31. https://doi.org/10.1080/10705511.2014.955104

Barkhuizen, N., Rothmann S., \& Van de Vijver F.J.R. (2014). Burnout and work engagement of academics in higher education institutions: Effects of dispositional optimism. Stress and Health, 30(4), 322-332. https://doi.org/10.1002/smi.2520

Berg, M., \& Seeber, B.K. (2016). The slow professor: Challenging the culture of speed in the academy. Toronto: University of Toronto Press.

Bowling, N.A., Alarcon, G.M., Bragg, C.B., \& Hartman, M.J., (2015). A meta-analytic examination of the potential correlates and consequences of workload. Work \& Stress: An International Journal of Work, Health \& Organizations, 29(2), 95-113. https://doi.org/10.1080/02678373.2015.1033037

Cameron, K.S. (2008). Paradox in positive organizational change. Journal of Applied Behavioral Science, 44(1), 7-24. https://doi.org/10.1177/0021886308314703

Cameron, K.S. (2010). Five keys to flourishing in trying times. Leader to Leader, 55 , 45-51. https://doi.org/10.1002/ltl.401

Cameron, K.S. (2011). Responsible leadership as virtuous leadership. Journal of Business Ethics, 98(S1), 25-35. https://doi.org/10.1007/s10551-011-1023-6

Cameron, K.S., Bright, D., \& Caza, A. (2004). Exploring the relationships between organizational virtuousness and performance. American Behavioral Scientist, 47(6), 766-790. https://doi.org/10.1177/0002764203260209

Cameron, K., Mora, C., Leutscher, T., \& Calarco, M. (2011). Effects of positive practices on organizational effectiveness. The Journal of Applied Behavioral Science, 47(3), 266-308. https://doi.org/10.1177/0021886310395514

Carmeli, A., Jones, C.D., \& Binyamin, G. (2016). The power of caring and generativity in building strategic adaptability. Journal of Occupational and Organizational Psychology, 89(1), 46-72. https://doi.org/10.1111/joop.12106

Caza, A., \& Cameron, K.S. (2008). Positive organizational scholarship: What does it achieve? In C.L. Cooper \& S. Clegg (Eds.), The Sage handbook of organizational behavior (Vol. 2, pp. 99-116). Thousand Oaks, CA: Sage.

Clark, A., \& Sousa, B. (2018). How to be a happy academic. London: Sage.

Clark, S.L. (2010). Mixture modeling with behavioral data. Doctoral dissertation. Los Angeles, CA: University of California.

Cox, S.S., Bennett, R.J., Tripp, T.M., \& Aquino, K. (2012). An empirical test for forgiveness motives' effects on employees' health and well-being. Journal of Occupational Health Psychology, 17(3), 330-340. https://doi.org/10.1037/a0028314

De Gieter, S., \& Hofmans, J. (2015). How reward satisfaction affects employees' turnover intentions and performance: An individual differences approach. Human Resource Management Journal, 25(2), 200-216. https://doi.org/10.1111/1748-8583.12072

Deci, E.L., \& Ryan, R.M. (2011). Levels of analysis: Regnant causes of behavior and well-being: The role of psychological needs. Psychological Inquiry, 22(1), 17-22. https://doi.org/10.1080/1047840X.2011.545978

Demerouti, E., \& Bakker, A.B. (2011). The job demands-resources model: Challenges for future research. South African Journal of Industrial Psychology, 37(2), 1-9. https://doi.org/10.4102/sajip.v37i2.974

Demerouti, E., Bakker, A.B., Nachreiner, F., \& Schaufeli, W.B. (2001). The job demands resources model of burnout. Journal of Applied Psychology, 86(3), 499-512. https://doi.org/10.1037/0021-9010.86.3.499

Fouché, E. (2015). Well-being of teachers in secondary schools. Unpublished doctora thesis. North-West University, Vanderbijlpark.

Gabriel, A.S., Daniels, M.A., Diefendorff, J.M., \& Greguras, G.J. (2015). Emotional labour actors: A latent profile analysis of emotional labor strategies. Journal of Applied Psychology, 100(3), 863-879. https://doi.org/10.1037/a0037408

Gabriel, A.S., Diefendorff, J.M., Chandler, M.M., Moran, C.M., \& Greguras, G.J. (2014) The dynamic relationships of work affect and job satisfaction with perceptions of fit. Personnel Psychology, 67(2), 389-420. https://doi.org/10.1111/peps.12042

Geue, P.E. (2018). Positive practices in the workplace: Impact on team climate, work engagement and task performance. Journal of Applied Behavioral Science, 54(3), 272-201. https://doi.org/10.1177/0021886318773459 
Greguras, G.J., \& Diefendorff, J.M. (2009). Different fits satisfy different needs: Linking person-environment fit to employee commitment and performance using self- determination theory. Journal of Applied Psychology, 94(2), 465-477. https:// self- determination theory.
doi.org/10.1037/a0014068

Harter, J., \& Adkins, A. (2015). What great managers do to engage employees. Harvard Business Review. Retrieved from https://hbr.org/2015/04/what-great-managersdo-to-engage-employees

Hoffman, B.J., \& Woehr, D.J. (2006). A quantitative review of the relationship between person-organization fit and behavioural outcomes. Journal of Vocational Behavior, 68(3), 389-399. https://doi.org/10.1016/j.jvb.2005.08.003

IBM Corp. (2017). IBM SPSS statistics: Version 25. Armonk, NY: IBM Corp.

Jung, T., \& Wickrama, K.A.S. (2008). An introduction of latent class growth analysis and growth mixture modeling. Social and Personality Psychology Compass, 2(1) 302-317. https://doi.org/10.1111/j.1751-9004.2007.00054.x

Kahn, W.A. (1990). Psychological conditions of personal engagement and disengagement at work. Academy of Management Journal, 33(4), 692-724. https://doi.org/10.5465/256287

Kahn, W.A., \& Heaphy, E.D. (2014). Relational contexts of personal engagement at work. In C. Truss, R. Delbridge, E. Soane, K. Alfes \& A. Shantz (Eds.), Employee engagement in theory and practice (pp. 82-96). Abingdon: Routledge.

Keyes, C.L.M. (2002). The mental health continuum: From languishing to flourishing in life. Journal of Health and Social Behavior, 43(2), 207-222. https://doi. org $/ 10.2307 / 3090197$

Keyes, C.L.M. (2005). Mental illness and/or mental health? Investing axioms of the complete state model of health. Journal of Consulting and Clinical Psychology, 73(3), 539-548.

Keyes, C.L.M. (2007). Promoting and protecting mental health as flourishing A complementary strategy for improving national mental health. American Psychologist, 62(2), 95-108. https://doi.org/10.2307/3090197

Keyes, C.L.M. (2009). Brief description of the mental health continuum short form (MHC-SF). Retrieved from https//www.sociology.emory.edu/ckeyes/

Keyes, C.L.M., \& Annas, J. (2009). Feeling good and functioning well: Distinctive concepts in ancient philosophy and contemporary science. Journal of Positive
Psychology, 4(3), 197-201. https://doi.org/10.1080/17439760902844228

Kinman, G. (2001). Pressure points: A review of research on stressors and strains in UK academics. Educational Psychology, 21(4), 473-492. https://doi.org/10.1080/ 01443410120090849

Kristof-Brown, A.L., \& Billsberry, J. (2013). Fit for future. In A.L. Kristof-Brown \& J. Billsberry (Eds.), Organizational fit: Key issues and new directions (pp. 1-18). Malden, MA: Wiley.

Kristof-Brown, A.L., Zimmerman, R.D., \& Johnson, E.C. (2005). Consequences of individuals; fit at work: A meta-analysis of person-job, person-organization, person-group, and person-supervisor fit. Personnel Psychology, 58(2), 281-342.

Liao, K.Y., \& Weng, C. (2018). Gratefulness and subjective well-being: Social connectedness and presence of meaning as mediators. Journal of Counselling Psychology, 65(3), 383-393. https://doi.org/10.1037/cou0000271

Lo, Y., Mendell, N.R., \& Rubin, D.B. (2001). Testing the number of components in a normal mixture. Biometrika, 88(3), 767-778. https://doi.org/10.1093/biomet/88.3.767

Lyubomirsky, S., King, L., \& Diener, E. (2005). The benefits of frequent positive affect: Does happiness lead to success? Psychological Bulletin, 131(6), 803-855. https:// doi.org/10.1037/0033-2909.131.6.803

Madden, L.T., Duchon, D., Madden, T.M., \& Plowman, D.A. (2012). Emergent organizational capacity for compassion. Academy of Management Review, 37(4), 689-708. https://doi.org/10.5465/amr.2010.0424

Mahomed, F.E., \& Rothmann, S. (2019). From surviving to thriving: Towards career well-being. In I. Potgieter \& M. Coetzee (Eds.), Theory, research and dynamics of career wellbeing: Becoming fit for the future (pp. 91-116). Cham: Springer Nature.

Muthén, L.K., \& Muthén, B.O. (1998-2019). Mplus users' guide (9th edn.). Los Angeles, CA: Muthén \& Muthén.

Nunnally, J.C., \& Bernstein, I.H. (1994). Psychometric theory (3rd edn.). New York: McGraw-Hill.

Nylund-Gibson, K., Asparouhov, T., \& Muthén, B.O. (2007). Deciding on the number of classes in latent class analysis and growth mixture modeling: A Monte Carlo simulation study. Structural Equation Modeling: A Multidisciplinary Journal, 14(4), 535-569. https://doi.org/10.1080/10705510701575396
Panaccio, A., \& Vandenberge, C. (2011). The relationships of role clarity and organization-based self-esteem to commitment to supervisors and organizations and turnover intentions. Journal of Applied Social Psychology, 41(6), 1455-1485. https://doi.org/10.1111/j.1559-1816.2011.00764.x

Peterson, C., \& Seligman, M.E.P. (2004). Character strengths and virtues. New York: Oxford University Press.

Quinn, R. (2015). The positive organization: Breaking free from conventional cultures, constraints, and beliefs. Oakland, CA: Berrett-Koehler Publishers.

Raykov, T. (2009). Interval estimation of revision effect on scale reliability via covariance structure analysis. Structural Equation Modeling, 16(3), 539-555. https://doi.org/10.1080/10705510903008337

Redelinghuys, K., Rothmann, S., \& Botha, E. (2018). Flourishing-at-work: The role of positive organizational practices. Psychological Reports, 122(2), 609-631. https:// doi.org/10.1177/0033294118757935

Rautenbach, C. (2015). Flourishing of employees in a fast-moving consumable goods environment (Doctoral thesis). Vanderbijlpark: North-West University.

Rothmann, S. (2013). From happiness to flourishing at work: A Southern African perspective. In M.P. Wissing (Ed.), Well-being research in South Africa: Crosscultural advances in positive psychology (Vol. 4, pp. 123-151). Dordrecht: Springer.

Rothmann, S. (2014a). Flourishing in work and careers. In M. Coetzee (Ed.), Psychosocial career meta-capacities: Dynamics of contemporary career development (pp. 203-220). Dordrecht: Springer.

Rothmann, S. (2014b). Positive institutions. In M.P. Wissing, J.C. Potgieter, L. Nel, I.P. Khumalo, \& T. Guse (Eds.), Towards flourishing: Contextualising positive psychology (pp. 231-262). Pretoria: Van Schaik.

Rothmann, S. (2015). Career experiences. In A.M.G. Schreuder \& M. Coetzee (Eds.), Career psychology (pp. 351-399). Johannesburg: Van Schaik.

Rothmann, S., Mostert, K., \& Strydom, M. (2006). A psychometric evaluation of the job demands-resources scale in South Arica. South African Journal of Industrial Psychology, 32(4), 76-86. https://doi.org/10.4102/sajip.v32i4.239

Ryan, R.M., \& Deci, E.L. (2001). On happiness and human potentials: A review of research on hedonic and eudaimonic well-being. Annual Review of Psychology, 52(1), 141-166. https://doi.org/10.1146/annurev.psych.52.1.141

Ryan, S. (2012). Academic zombies: A failure of resistance or a means of survival. Australian Universities Review, 54(2), 3-11.

Spector, P.E. (2019, online). Do not cross me: Optimizing the use of cross-sectional designs. Journal of Business and Psychology, 34, 1-13.

Spreitzer, G., \& Sonenshein, S. (2003). Positive deviance and extraordinary organizing. In K.S Cameron, J.E. Dutton, \& R.E. Quinn (Eds.), Positive organizational scholarship: Foundations of a new discipline (pp. 207-226). San Francisco, CA: Berrett-Koehler.

Su, R., Murdock, C.D., \& Rounds, J. (2015). Person-environment fit. In P.J. Hartung, M.L. Savickas \& W.B. Walsh (Eds.), APA handbook of career interventions (pp. 81-89). Washington, DC: American Psychological Association.

Van Vianen, A.E.M., Stoelhorst, J.W., \& De Goede, M.E.E. (2013). The construal of person-organization fit during the ASA stages. In A.L. Kristof-Brown \& J. Billsberry (Eds.), Organizational fit: Key issues and new directions (pp. 145-169). Malden, MA: Wiley.

Verquer, M.L., Beehr, T.A., \& Wagner, S.H. (2003) A meta-analysis of relations between person-organization fit and work attitudes. Journal of Vocational Behavior, 63(3), 473-489. https://doi.org/10.1016/S0001-8791(02)00036-2

Wang, J., \& Wang, X. (2012). Structural equation modeling: Applications using Mplus. Chichester: Wiley.

West, S.G., Taylor, A.B., \& Wu, W. (2012). Model fit and model selection in structural equation modeling. In R.H. Hoyle (Ed.), Handbook of structural equation modeling (pp. 209-231). New York: The Guilford Press.

Winter, R., Taylor, T., \& Sarros, J. (2000). Trouble at mill: Quality of academic worklife issues within a comprehensive Australian university. Studies in Higher Education 25(3), 279-294. https://doi.org/10.1080/713696158

Zdaniuk, A., \& Bobocel, D.R. (2015). The role of idealized influence leadership in promoting workplace forgiveness. The Leadership Quarterly, 26(5), 863-877. https://doi.org/10.1016/j.leaqua.2015.06.008 